\title{
A New Guide Wave Inspection System Using Three Polarized Transverse Wave EMATs without Any Couplant
}

\section{Riichi Murayama}

Faculty of Engineering, Fukuoka Institute of Technology, Fukuoka, Japan

Email: murayama@fit.ac.jp

How to cite this paper: Murayama, R. (2016) A New Guide Wave Inspection System Using Three Polarized Transverse Wave EMATs without Any Couplant. Journal or Sensor Technology, 6, 110-121.

http://dx.doi.org/10.4236/jst.2016.64009

Received: September 2, 2016

Accepted: October 24, 2016

Published: October 27, 2016

Copyright $\odot 2016$ by author and Scientific Research Publishing Inc. This work is licensed under the Creative Commons Attribution International License (CC BY 4.0).

http://creativecommons.org/licenses/by/4.0/

\begin{abstract}
A guide wave is provided with the characteristic of long range propagation in the axis direction of a pipe, so it is possible to detect many defects over a large pipe area at once. At present, there is a technique to generate a guide wave using a piezoelectric element (PZT). However, the transverse wave-transducer using PZT needs to require a high viscosity couplant because the transverse wave cannot travel into typical liquid like water or oil. A guide wave inspection system that uses an electromagnetic ultrasonic transducer (EMAT) which does not require any couplant has then been developed to solve this trouble. First, a guide wave into a pipe, L, T and F-mode, can be transmitted and received by a polarized shear horizontal transverse wave propagating to the thickness direction when the vibration direction has been adjusted to the best direction. At next stage, the three EMATs for L, T and F-mode with different polarized vibration directions were piled up to improve the performance at the same position under the permanent magnet to inspect the pipe at the same condition. Next, the system with the EMATs can be confirmed to be able to detect three guide wave modes signal with enough intensity. Finally, the detection performance using the test pipes with any artificial defects has been done by the developed pipe inspection system, and any drilled holes and any notches can be detected. It is indicated that the developed system could be useful in real industrial field.
\end{abstract}

\section{Keywords}

Guide Wave, Transverse Wave, EMAT, Nondestructive Inspection, Pipe

\section{Introduction}

A lot of pipes have been used for carrying fuel oil, natural gas, etc. for human life, or as 
a heat exchanger such as a power plant. However, such pipes sometimes break in due to the corrosion or other damages during long range use. It must be avoided for the safety and the efficiency for the human life definitely. Therefore, nondestructive inspection of such pipes is strongly required. As one of the inspection methods, the use of the guide wave has been popular in recent years. The guide wave propagates along the axis direction of a pipe without attenuation of the ultrasonic power. That is, it features the longrange propagation to the axis direction of a pipe, which makes it possible to detect some defects over a broad range [1]-[5]. A lot of features in a guide wave have been researched to use a guide wave effectively [6]. Furthermore, it has been also investigated how to propagate at the curved part of a pipe [7] [8]. Especially, it is observed that a new phenomenon that other guide waves traveling to the circumferential direction can be generated when a guide wave traveling to the axis direction hits at any defects in a pipe [9]. Detective ability has also been investigated by many researchers [10] [11].

The guide wave inspection system using a polarized transverse wave with a PZT type transducer has already been developed and used in an application field. However, such an ultrasonic sensor requires a couplant with a high viscosity. This makes it difficult to move along the axis direction of a pipe. The inspection system, which can transmit and receive the guided wave using the electromagnetic ultrasonic acoustic wave transducer (EMAT) that injects the polarized traverse waves in the pipe thickness direction, was then developed. Using the developed system, we were able to use the lowest order of the L, T, and F-modes guide waves which are the typical modes of a guided wave travelling into a pipe [12]. However, there has been a question about the first trial inspection system, that is, each guide wave mode might have been driven under different conditions because three EMATs have been placed at the different position on the pipe. The inspection system with the new EMAT to solve this problem has then been developed. The outline of the new system and the experimental results have been shown in the paper.

\section{Lowest Order of L, T, F Mode Guide Wave}

A guide wave is a type of interference wave of the ultrasonic wave propagating in the pipe axis direction. As shown in Figure 1, for the lowest order mode, they have the following oscillation characteristics in them. That is, for the L-mode, the vibration direction is parallel to the propagation direction. The T-mode operates in the vertical vibration direction to the propagation direction and in a parallel direction to the surface of the pipe. Finally, the F-mode operates in the slant vibration direction to the propagation direction and parallel to the surface [13]. That is, it is postulated that they can have different detecting abilities. We then decided to develop a new pipe inspection system that can alternately use the 3 modes.

\section{Fundamental Idea of a Trial Guide Wave Transmitter and Receiver System}

The drive principle of a polarized traverse-wave EMAT is shown in Figure 2. It consists 


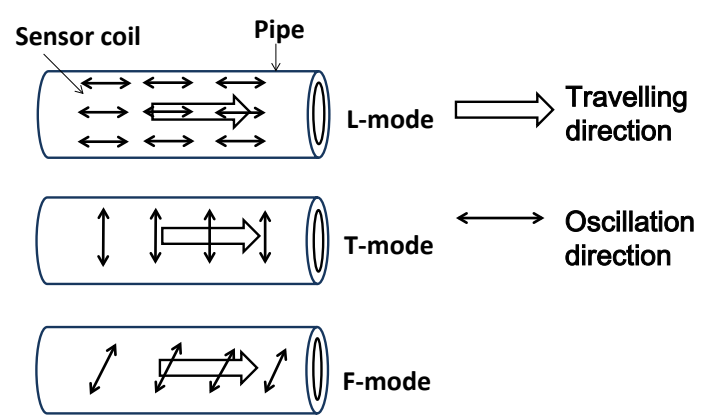

Figure 1. 3 modes of a guided wave.

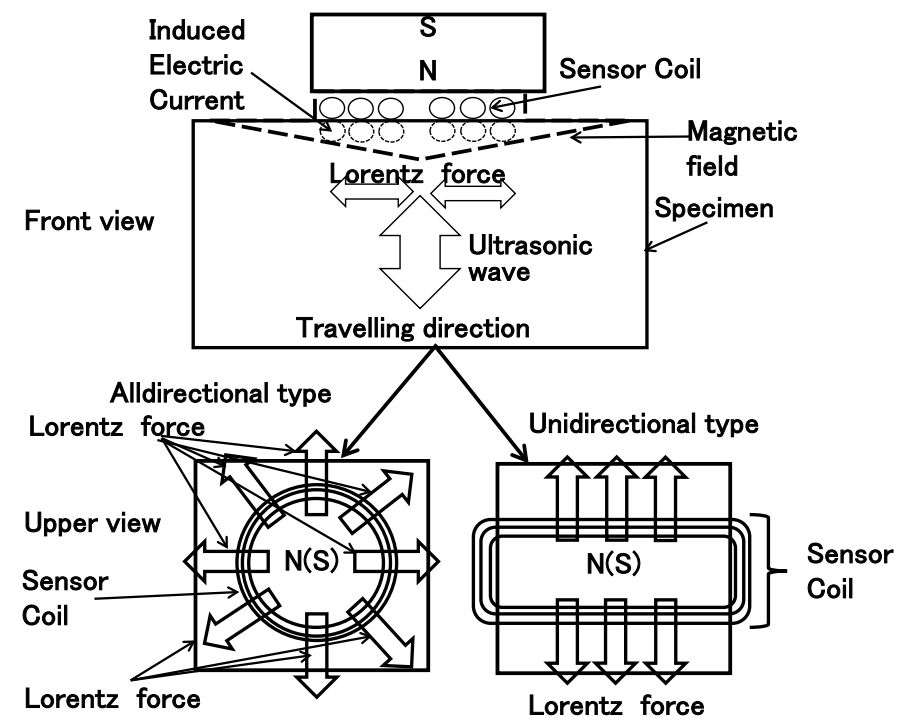

Figure 2. Non-polarized and polarized transverse wave EMAT.

of a single permanent magnet which applies a magnetic field in the thickness direction and an electromagnetic induction coil which applies an eddy current in the surface direction on the surface of a metal material under the EMAT. A Lorentz force is then generated in the horizontal direction on the surface and to the vertical direction of eddy current direction according to Fleming's left hand law. The Lorentz force is periodically changed according to the high-frequency vibration of an eddy current on the high frequency electric current in the electromagnetic induction coil. It then converts into a transverse wave. Especially, the vibration is limited to one direction if the direction of the eddy current is in one direction. Such an eddy current can be generated using a rectangular-shaped coil or an ellipse-shaped coil. A transverse wave with any vibration direction can be generated by rotating such an EMAT placed on the metal material in any direction [14] [15].

Figure 3 shows the basic idea of the trial guide wave-sensor. The polarized transverse wave in any direction can be generated by rotating the polarized transverse EMATs. For the L-mode guide wave, the polarized EMATs, whose polarized direction is parallel to the axis direction, are placed on the surface of a pipe with the same interval in the circumferential direction of the pipe. When these EMATs are driven, the interference 


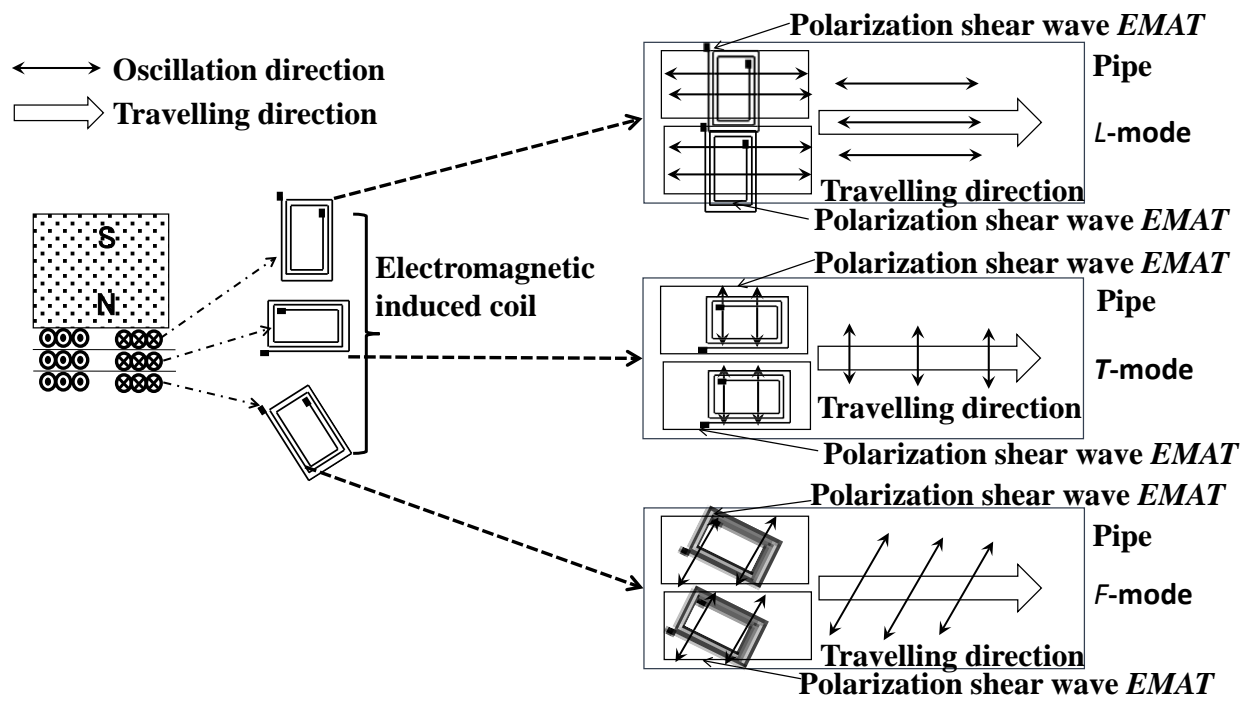

Figure 3. Three modes guide wave system using polarized EMATs.

in the thickness direction and the circumferential direction can be generated. As a result, an L-mode guide wave may be injected. For the T-mode guide wave, pieces of polarized EMATs, whose polarized direction is vertical to the axis direction, is placed on the surface of a pipe with the same interval to the circumferential direction. For the F-mode guide wave, the polarized EMAT, whose polarized direction is inclined in the axis direction, is placed on the surface of a pipe with the same interval in the circumferential direction. As a result, the F-mode guide wave may be injected. Three rectangle shaped electromagnetic induction coils with different direction are placed at the same position on the surface of the permanent magnet. That is, the system can inspect at high speed using a multichannel pulser and receiver equipment. However, the experimental results using a single pulser and receiver system are indicated on the paper [16] [17] [18].

\section{Guide Wave Generation on the Metal Surface by a Polarized Transverse Wave Propagating to the Thickness Direction Using Two-Dimensional Differential Method}

Guided wave generated by using the polarized transverse wave propagating in the vertical direction was confirmed using a two-dimensional difference method. Thin plate model is shown in Figure 4, the mesh space in the thickness direction was divided into 10 pieces and divided into 800 pieces longitudinally. Motion equation used for the difference method is as shown in Equation (1).

$$
\begin{aligned}
& \rho \partial^{2} u / \partial t^{2}=(\lambda+2 \mu) \partial^{2} u / \partial x^{2}+(\lambda+\mu) \partial^{2} v / \partial x \partial y+\mu \partial^{2} u / \partial y^{2}+F_{x} \\
& \rho \partial^{2} v / \partial t^{2}=(\lambda+2 \mu) \partial^{2} v / \partial x^{2}+(\lambda+\mu) \partial^{2} u / \partial x \partial y+\mu \partial^{2} v / \partial y^{2}+F_{y}
\end{aligned}
$$

$\rho$ : Density, $\lambda, \mu$ : Lame constant, $u, v$ : Displacement in $x, y$ directions, $F_{x}, F_{y}$ : Drive force for $x, y$ directions

Equations (2)-(9) show the basic equation using the differential method. $F_{Y}$ was as- 
sumed as $0(\mathrm{~N})$ and the $F_{x}$ was added as sine wave force with two period only 20 meshes at the center position as shown in Equation (9). It is determined that $\Delta x$ and $\Delta y=0.2$ $\mathrm{mm}$. It was then decided that $\Delta t$ was $0.02 \mu$ s after the trial simulation while changing the $\Delta t$.

$$
\begin{gathered}
\partial u^{2} / \partial t^{2}=u_{i, j} / \Delta t^{2} \\
\partial v^{2} / \partial t^{2}=v_{i, j} / \Delta t^{2} \\
\partial u^{2} / \partial x^{2}=\left(u_{i-1, j}-2 u_{i, j}+u_{i+1, j}\right) / \Delta x^{2} \\
\partial u^{2} / \partial y^{2}=\left(u_{i, j-1}-2 u_{i, j}+u_{i, j+1}\right) / \Delta y^{2} \\
\partial v^{2} / \partial x^{2}=\left(v_{i-1, j}-2 v_{i, j}+v_{i+1, j}\right) / \Delta x^{2} \\
\partial v^{2} / \partial y^{2}=\left(v_{i, j-1}-2 v_{i, j}+v_{i, j+1}\right) / \Delta y^{2} \\
\partial v^{2} / \partial x \partial y=\left(v_{i-1, j}+v_{i+1, j}-4 v_{i, j}+v_{i, j+1}+v_{i, j-1}\right) / \Delta x \Delta y
\end{gathered}
$$

i: $1-800, j: 1-800$

$$
F_{x}(i, j)=a \cdot \sin (2 \pi f \cdot t), \quad F_{y}(i, j)=0(\mathrm{~N})
$$

a: constant $(\mathrm{N}), i=291-310, j=1$.

As a result, the intensity of the guided wave to arrive at the right end of Figure 4 shows the analysis result while changing the frequency of the driving force as shown in Figure 5. It is confirmed that the guide waves using polarized shear wave propagating to the thickness direction could be generated and became maximum intensity at the drive frequency of $180 \mathrm{kHz}$. In other words, the use under the drive frequency $200 \mathrm{kH}$ is, can be presumed to be effective in guided wave generation.

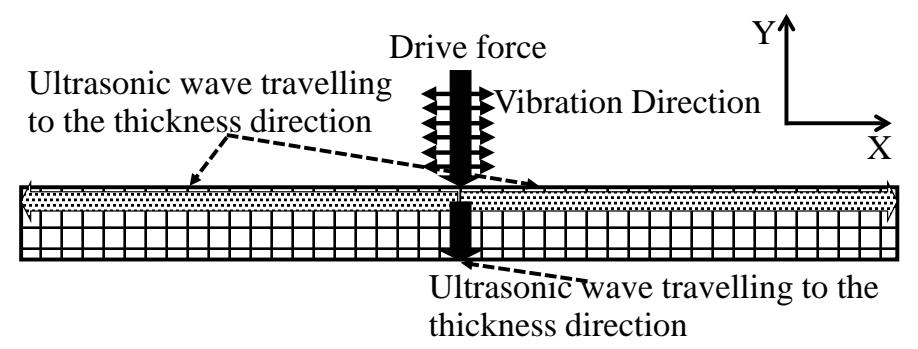

Figure 4. Simulation condition using 2-dimensional differential method.

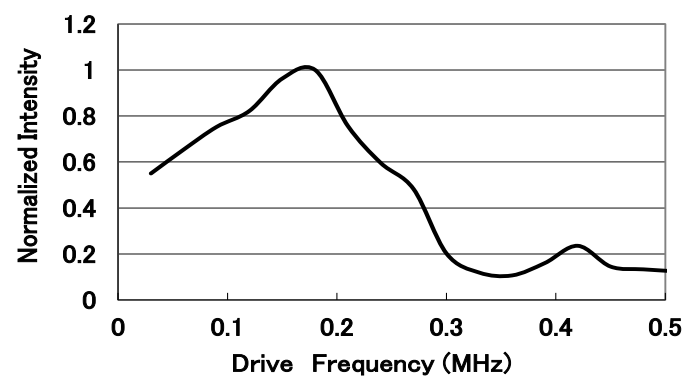

Figure 5. Analysis result by the simulation. 


\section{Optimization of Unidirectional Polarized Transverse-EMAT}

The specification of an electromagnetic induction coil which constitutes the EMAT was evaluated using the thickness signal of a $60 \mathrm{~mm}$ thick aluminum block with $100 \mathrm{~mm}$ width and $100 \mathrm{~mm}$ length. The magnetic flux intensity of the used permanent magnet was $0.45 \mathrm{~T}$. The magnet was the neodymium type with a $20 \mathrm{~mm}$ width, $30 \mathrm{~mm}$ length, and $20 \mathrm{~mm}$ height. Two magnets were used as one pair.

Figure 6 shows the signal intensities using the three optimum electromagnetic induction coils when they piled up on the permanent magnet arranged in the three direction. Although the signal intensity by the upper coil decreased because there is gap of about $0.2 \mathrm{~mm}$ due to an insert paper used to insult between the electromagnetic induction coils, every received signal intensity is over S/N. Figure 7 shows the received signal waveform example using the electromagnetic induction coil far side from the aluminum specimen surface and the $\mathrm{S} / \mathrm{N}$ was over 10.

\section{L, T, and F Mode Guided Wave System}

The experimental system as shown in Figure 8 consisted of a pulser, which input a high frequency and high power electric current with a burst shape, an amplifier, which amplifies the signal by $80 \mathrm{~dB}$, and selects the drive frequency between $70 \mathrm{kHz}$ to $1 \mathrm{MHz}$, and an oscilloscope and CPU which observes and evaluates the received signal. Many

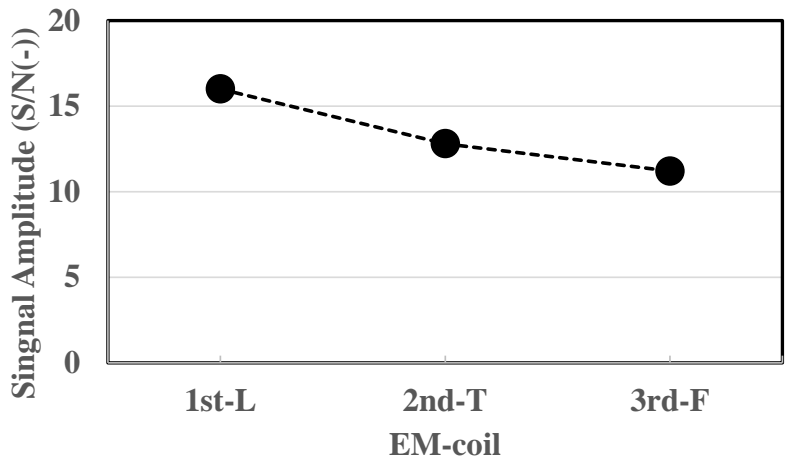

Figure 6. Principle of shear wave vertical EMAT.

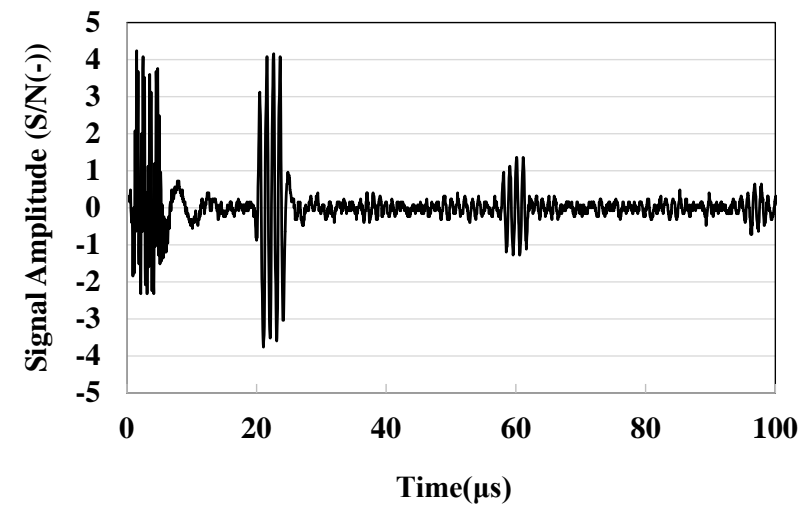

Figure 7. Signal amplitude and the best specification of the coil. 


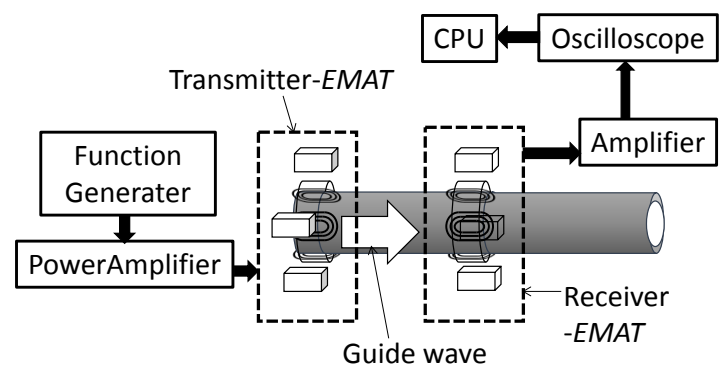

Figure 8. Experimental system.

drive conditions were tested in order to obtain a good received signal as the nondestructive inspection using the guide wave system. As an example of the trial experiments in Figure 9, it was determined that it is best to drive the electromagnetic acoustic transducer at a $100 \mathrm{kHz}$ drive frequency. The maximum number of EMATs was optimized at 8 for an aluminum pipe with a $60 \mathrm{~mm}$ diameter based on the size of the EMAT. The relationship between the drive frequency and the group velocity of a guide wave for a $2 \mathrm{~mm}$ thick aluminum pipe is shown in Figure 10. When the $100 \mathrm{kHz}$ drive frequency was used, it was expected that $\mathrm{L}(0,2)$ was $5230 \mathrm{~m} / \mathrm{s}, \mathrm{T}(0,1)$ was $3130 \mathrm{~m} / \mathrm{s}$, and the $\mathrm{F}(0,1)$ mode was $2780 \mathrm{~m} / \mathrm{s}$ [5]. The received signals after the adjustment are shown in Figures $11-13$. The received signal by $\mathrm{T}(0,1)$ mode was the best.

\section{Evaluation of Flaw Detection Ability}

In order to evaluate the flaw detection ability using the developed guided wave inspection system for pipes, the circumferential notch in which the angle of 360 degrees to the circumferential direction with depth of $0.5 \mathrm{~mm}$ to $1.5 \mathrm{~mm}$, penetration drill holes with diameters from $1 \mathrm{~mm}$ to $20 \mathrm{~mm}$, and the 30 degrees-slant notches with depth of 0.5 $\mathrm{mm}$ to $1.5 \mathrm{~mm}$ were machined as shown in Figure 14.

The results for the circumferential notches with $1.5 \mathrm{~mm}$ depth and $0.5 \mathrm{~mm}$ depth are shown in Figure 15. Reflection ratio was the biggest in the case of F-mode guide wave, although the reflection signal at the opposite side by T-mode guide wave was the biggest. The results for the drilled hole with $1 \mathrm{~mm}$ diameter and $5 \mathrm{~mm}$ diameter in Figure 16. It was almost same results in the case of the cylindrical notch.

Figure 17 indicated the distance attenuation coefficients in the case of the no-damage surface and the wet surface of the pipe. Even if the surface is wet or not, the coefficients by T-mode guide wave was the smallest. Therefore when the system inspect the pipe with more than $10 \mathrm{~m}$, T-mode guide wave will become helpful.

\section{Conclusion}

Guide waves have been used for the nondestructive inspection of a long pipe because they can travel a long distance along the axis direction of a pipe. However, there are no convenient sensors that can easily transmit and receive guide wave. We then tried to develop a convenient guide wave sensor using an electromagnetic acoustic transducer 


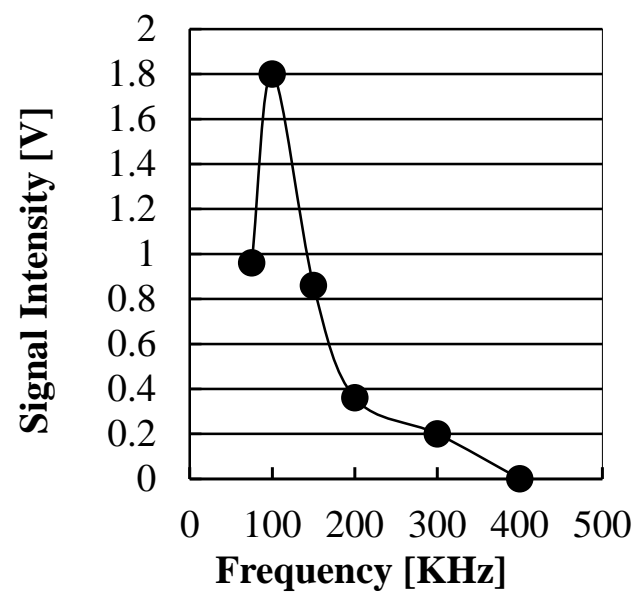

Figure 9. Signal amplitude and drive frequency.

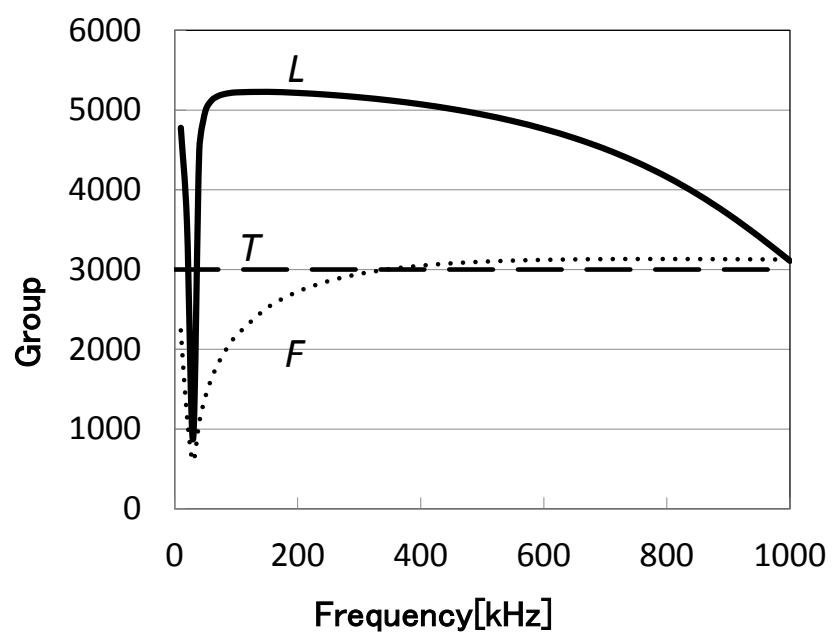

Figure 10. Velocity and drive frequency.

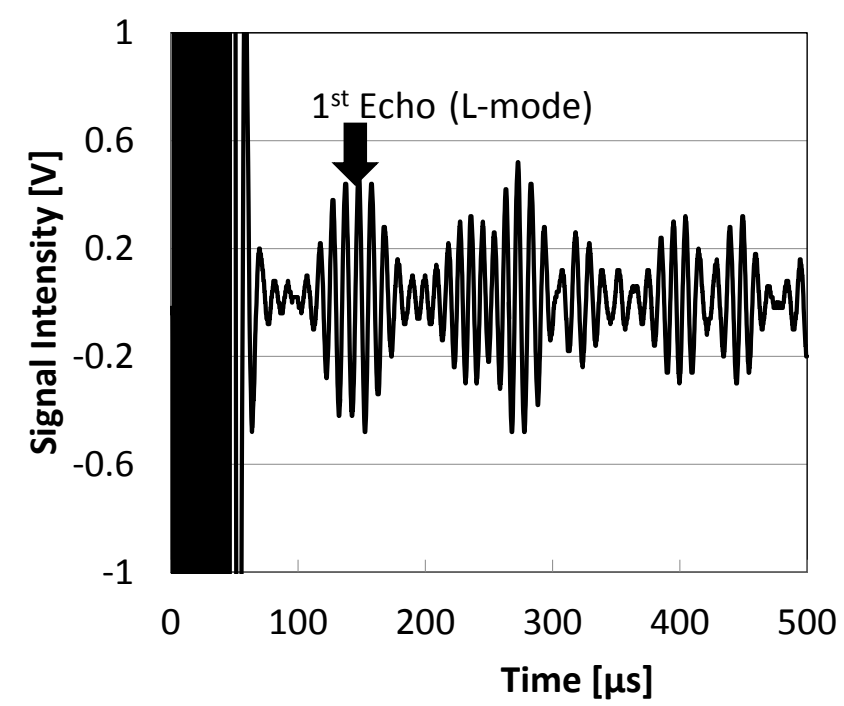

Figure 11. Signal example (L-mode). 


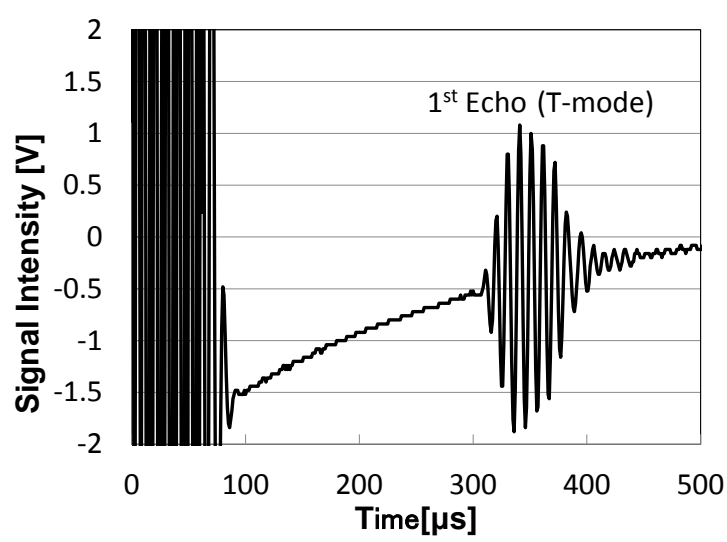

Figure 12. Signal example (T-mode).

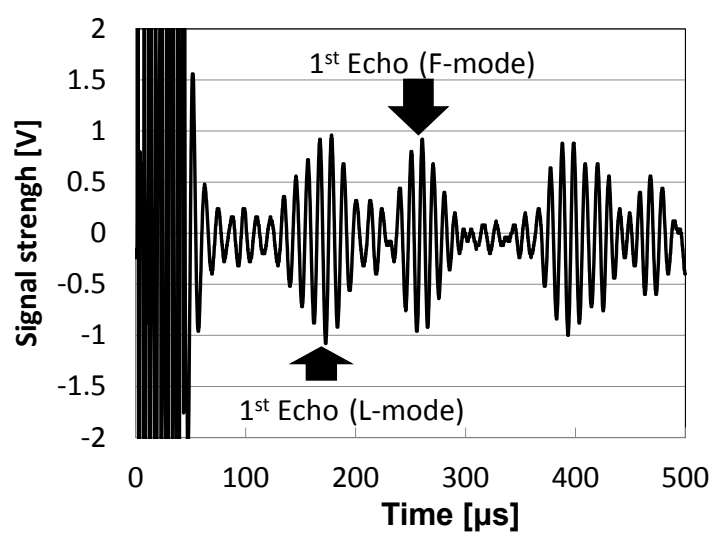

Figure 13. Signal example (F-mode).
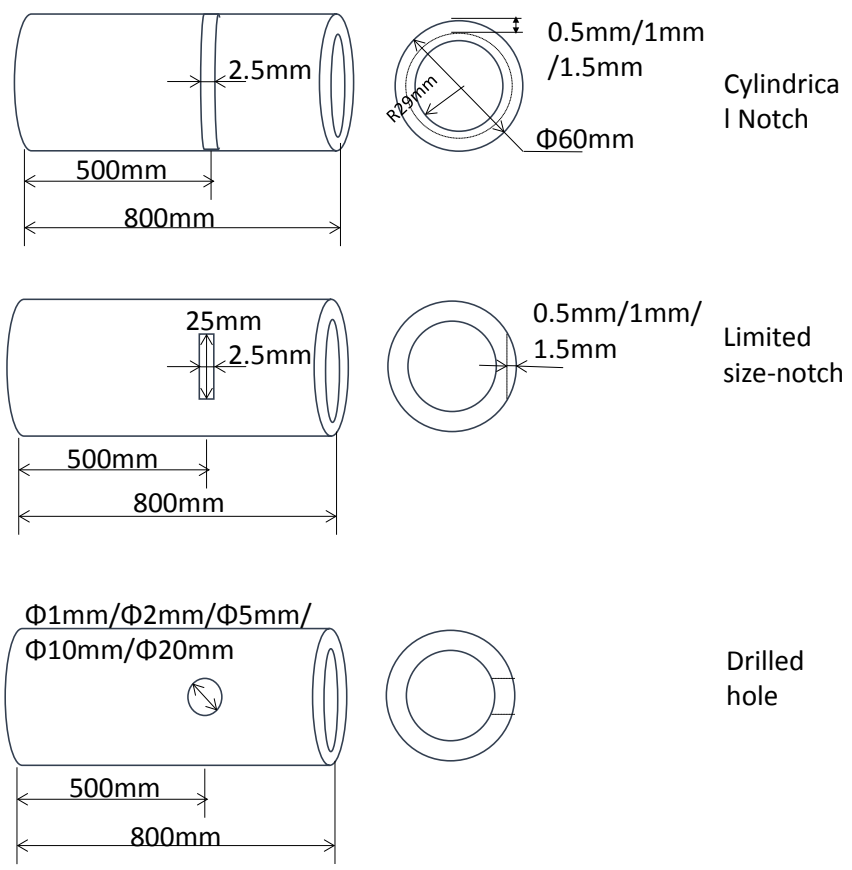

Figure 14. Outline of a pipe with artificial defects. 


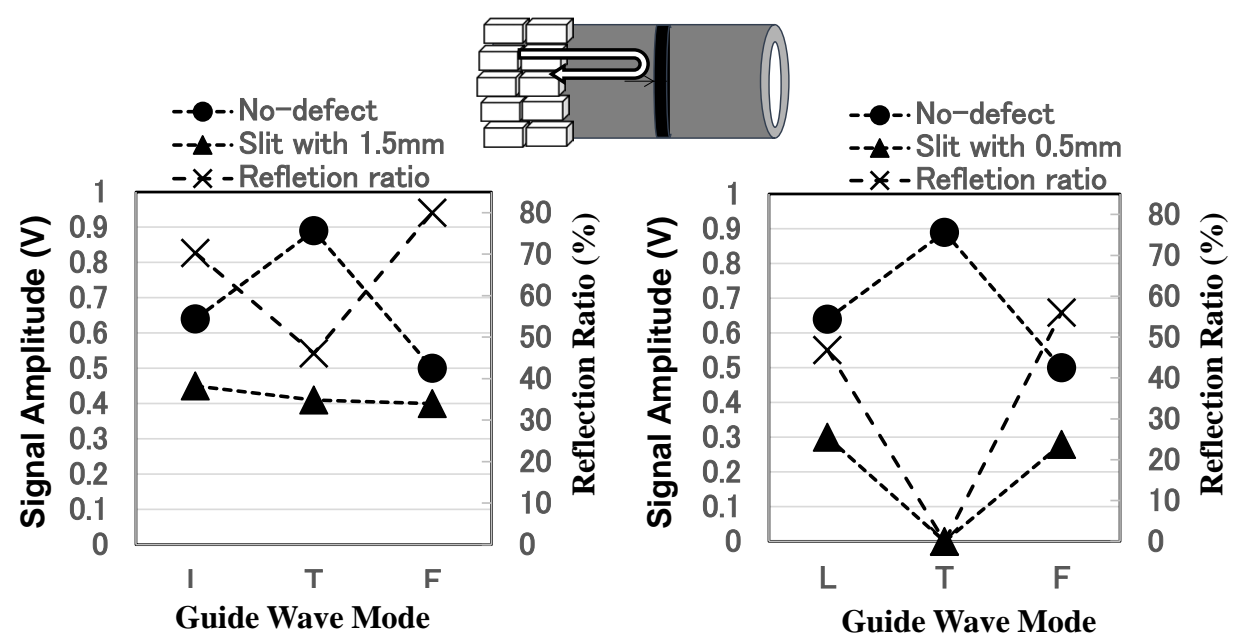

(a)

(b)

Figure 15. Signal amplitude and depth of a cylindrical notch. (a) $1.5 \mathrm{~mm}$ depth; (b) $0.5 \mathrm{~mm}$ depth.

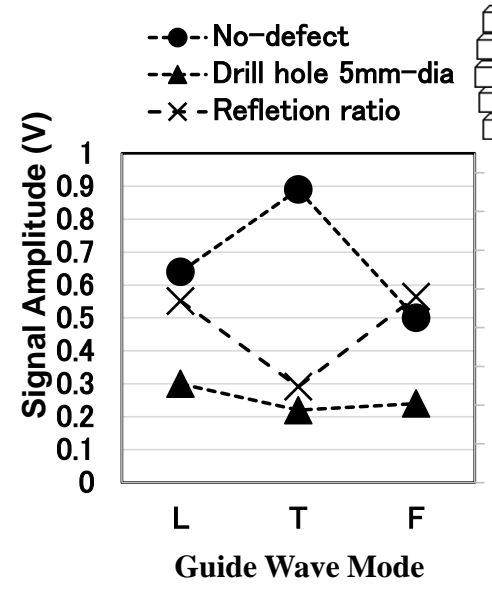

(a)

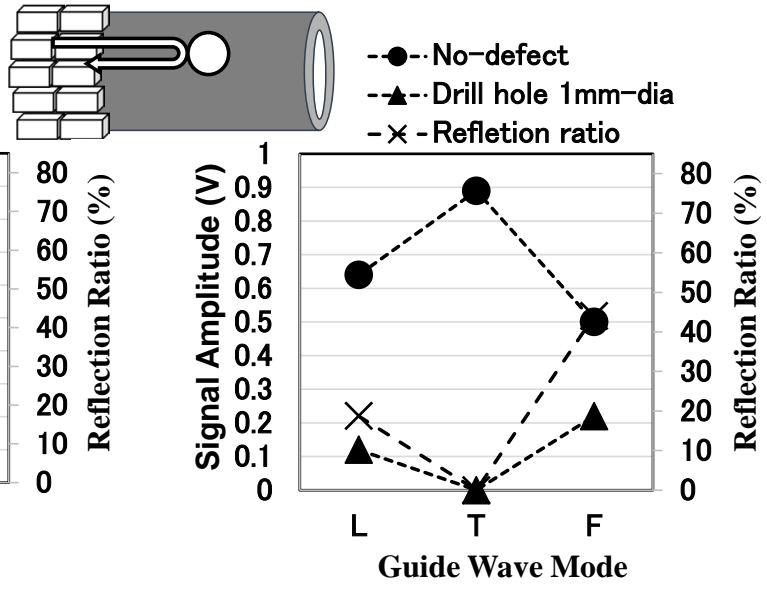

(b)

Figure 16. Signal amplitude and the diameter of drilled holes. (a) $5 \mathrm{~mm}$ diameter; (b) $1 \mathrm{~mm}$ diameter.

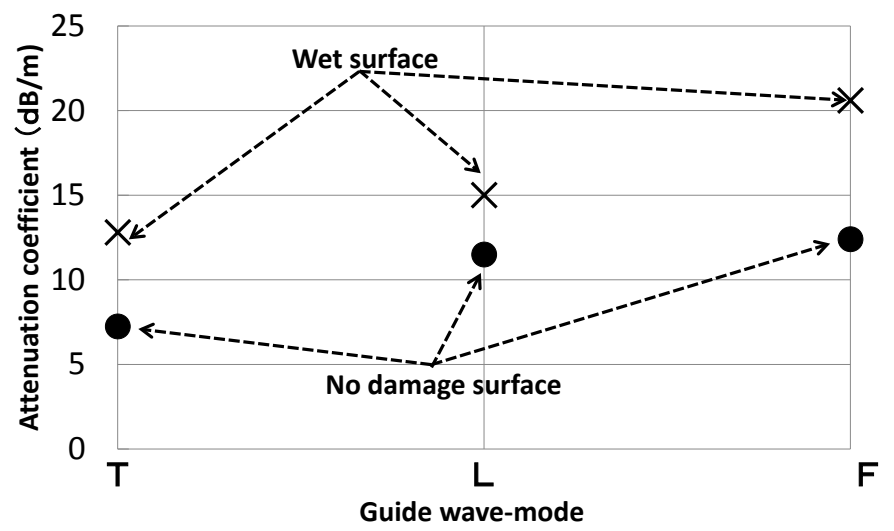

Figure 17. Attenuation coefficients under different conditions. 
(EMAT). The sensing system consists of 8 transverse wave-EMATs which are located around the pipe at every $45^{\circ}$. Each EMAT can generate transverse waves which vibrate in one direction. This means that such a system could generate many modes of guide waves if the EMATs are set in different directions on the pipe surface. At first, the best specification of the EMAT was experimentally examined. Next, the guide wave sensor system was fabricated using the optimum set of EMATs. As a conclusion, the system could detect L, T, F-mode guide wave. The performance to detect some defects, drilled holes and notches of different sizes and shapes were then evaluated. The experimental results indicated that each mode has a different performance to detect defects. This means that the best performance could be obtained by combining the 3 guide wave modes.

\section{Acknowledgements}

This study was partially supported by a Grant-In-Aid for Scientific Research from the Ministry of Education Culture, Sports, Science and Technology (C26420032).

\section{References}

[1] Rose, J.L. (1999) Ultrasonic Waves in Solid Media. Cambridge University Press, Cambridge.

[2] Silk, M.G. and Bainton, K. (1979) The Propagation in Metal Tubing of Ultrasonicwave Modes Equivalent to Lamb Waves. Ultrasonics, 17, 11-19. http://dx.doi.org/10.1016/0041-624X(79)90006-4

[3] Gazis, D.C. (1959) Three Dimensional Investigation of the Propagation of Waves in Hollow Circular Cylinders I. Analytical Foundation. The Journal of the Acoustical Society of America, 31, 568-573. http://dx.doi.org/10.1121/1.1907753

[4] Fitch, A.H. (1963) Observation of Elastic-Pulse Propagation in Axially Symmetric and Non-Axially Symmetric Longitudinal Modes of Hollow Cylinders. The Journal of the Acoustical Society of America, 35, 706-708. http://dx.doi.org/10.1121/1.1918594

[5] Hayashi, T., Kawashima, K., Sun, Z. and Rose, J.L. (2005) Guided Wave Propagation Mechanics across a Pipe Elbow. Journal of Pressure Vessel Technology, 127, 322-327. http://dx.doi.org/10.1115/1.1990210

[6] Alleyne, D.N. and Cawley, P. (1997) Long Range Propagation of Lamb Waves in Chemical Plant Pipework. Material Evaluations, 55, 504-508.

[7] Demma, A., Cawley, P. and Lowe, M. (2005) The Effect of Bends on the Propagation of Guided Waves in Pipes. Journal of Pressure Vessel Technology, 127, 328-335. http://dx.doi.org/10.1115/1.1990211

[8] Hishino, N. (2011) Experimental Investigation of Mode Conversions of the T(0,1) Mode Guided Wave Propagating in an Elbow Pipe. Japanese Journal of Applied Physics, 50, Article ID: 046601.

[9] Nishino, N., Kataoka, T., Morita, K. and Yoshida, K. (2011) Resonant Phenomena of Circumferential Lamb Waves Generated by Eight Transducer-Elements Located Evenly on the Circumference and Wall Thickness Measurements. Proceedings of Symposium on Ultrasonic Electronics, 32, 347-348.

[10] Lowe, M.J.S., Alleyne, D.N. and Cawley, P. (1998) Defect Detection in Pipes Using Guided Waves. Ultrasonics, 36, 147-154. http://dx.doi.org/10.1016/S0041-624X(97)00038-3 
[11] Alleyne, D.N. and Cawley, P. (1995) The Long Range Detection of Corrosion in Pipes Using Lamb Waves. Review of Progress in QNDE, 14, 2073-2080.

[12] Murayama, R., Sriratana, W., Imai, K., Sonoda, N. and Kobayash, M. (2014) Pipe Inspection System Using a Polarized Transverse Wave EMAT. International Conference on Experimental Mechanics 2013 and Twelfth Asian Conference on Experimental Mechanics, Proceedings of SPIE, 2 June 2014.

[13] Pavlakovic, B., Lowe, M., Alleyne, D. and Cawley, P. (1997) Disperse: A General Purpose Program for Creating Dispersion Curves. Review of Progress in QNDE, 16, 185-192. http://dx.doi.org/10.1007/978-1-4615-5947-4 24

[14] Thompson, R.B. (1973) A Model for the Electromagnetic Generation and Detection of Rayleigh and Lamb Wave. IEEE Transactions on Sonics and Ultrasonics, 20, 340-346. http://dx.doi.org/10.1109/T-SU.1973.29770

[15] Hirao, M. and Ogi, H. (2004) Development of EMAT Techniques in EMATS FOR SCIENCE AND INDUSTRY. Kluwer Academic Publishers, London, 13-82.

[16] Yamasaki, H. (1999) Generation and Detection of Longitudinal Wave in Steel Wires by Electromagnetic Acoustic Transducers. Transactions of the JSMEA, 65, 1038-1043. http://dx.doi.org/10.1299/kikaia.65.1038

[17] Kwun, H. and Bartels, K.A. (1998) Magnetostrictive Sensor Technology and Its Applications. Ultrasonics, 36, 171-178. http://dx.doi.org/10.1016/S0041-624X(97)00043-7

[18] Yamasaki, T., Motogi, S. and Ohtani, T. (2005) Long Range Inspection of Steel Pipe End by Electromagnetic Acoustic Transducer. Proceedings of Third US-Japan Symposium on Advancing Applications and Capabilities in NDE, Maui Prince Hotel, Maui Island, USA, 20-24 June 2005, 426-432.

\section{Submit or recommend next manuscript to SCIRP and we will provide best service} for you:

Accepting pre-submission inquiries through Email, Facebook, LinkedIn, Twitter, etc. A wide selection of journals (inclusive of 9 subjects, more than 200 journals)

Providing 24-hour high-quality service

User-friendly online submission system

Fair and swift peer-review system

Efficient typesetting and proofreading procedure

Display of the result of downloads and visits, as well as the number of cited articles

Maximum dissemination of your research work

Submit your manuscript at: http://papersubmission.scirp.org/

Or contact jst@scirp.org 